\title{
A Critical Analysis of the Role of Testosterone in Erectile Function: From Pathophysiology to Treatment-A Systematic Review
}

\author{
Andrea M. Isidori ${ }^{a}$, Jacques Buvat $^{b}$, Giovanni Corona ${ }^{c}$, Irwin Goldstein $^{d}$, Emmanule A. Jannini $^{e}$, \\ Andrea Lenzi ${ }^{a}$, Hartmut Porst ${ }^{f}$, Andrea Salonia $^{g}$, Abdulmaged M. Traish $^{h}$, Mario Maggi ${ }^{i, *}$ \\ a Sapienza University of Rome, Rome, Italy; ${ }^{\mathrm{b}}$ Centre ETPARP, Lille, France; ${ }^{\mathrm{c}}$ Maggiore-Bellaria Hospital, Bologna, Italy; ${ }^{\mathrm{d}}$ Alvarado Hospital, San Diego, CA, \\ USA; ${ }^{\mathrm{e}}$ University of L'Aquila, L'Aquila, Italy; ${ }^{\mathrm{f}}$ Private Urological/Andrological Practice, Hamburg, Germany; ${ }^{\mathrm{g}}$ University Vita-Salute San Raffaele, Milan, Italy; \\ ${ }^{\mathrm{h}}$ Boston University School of Medicine, Boston, MA, USA; ${ }^{\mathrm{i}}$ University of Florence, Florence, Italy
}

\section{Article info}

\section{Article history:}

Accepted August 16, 2013

Published online ahead of

print on August 29, 2013

\section{Keywords:}

Erectile dysfunction

PDE5

Hypogonadism

Aging

Sexual function

$5 \alpha$-reductase inhibitors

\begin{abstract}
Context: Androgen modulation of erectile function (EF) is widely accepted. However, the use of testosterone replacement therapy (TRT) in men with erectile dysfunction (ED) has generated an unprecedented debate.

Objective: To summarize the relevant data on the incidence, diagnosis, and management of ED coexisting with hypogonadism and to develop a pathophysiology-based treatment algorithm.

Evidence acquisition: We reviewed the relevant medical literature, with a particular emphasis on original molecular studies, prospective observational data, and randomized controlled trials performed in the past $20 \mathrm{yr}$.

Evidence synthesis: Testosterone modulates nearly every component involved in $\mathrm{EF}$, from pelvic ganglions to smooth muscle and the endothelial cells of the corpora cavernosa. It also regulates the timing of the erectile process as a function of sexual desire, coordinating penile erection with sex. Epidemiologic studies confirm the significant overlap of hypogonadism and ED; however, most guidelines do not consider the differential diagnosis of hypogonadism or the relevance of subclinical disease. Various clinical tools can help the physician to assess and restore androgen levels in men with ED. Special attention is given to fertility-sparing treatments, due to the increasing number of older men desiring fatherhood. The simultaneous use of phosphodiesterase type 5 inhibitors (PDE5-Is) and TRT has recently been questioned. Originally proposed as a salvage therapy for nonresponders to PDE5-Is, this approach has been inappropriately transformed into a combination therapy. Clinical data are consistent when reinterpreted in the proper framework, whereas molecular evidence remains controversial.

Conclusions: A body of molecular and clinical evidence supports the use of TRT in hypogonadal patients with ED, although the benefit-risk ratio is uncertain in advanced age. Critical appraisal of this evidence enabled the development of a pathophysiologyoriented algorithm designed to avoid inappropriate treatments and support whether to start with TRT, PDE5-I only, or both. Apparently divergent findings are reconciled when TRT is correctly indicated. An improved diagnosis and individualized management is desirable in light of the many available options.

(C) 2013 European Association of Urology. Published by Elsevier B.V. All rights reserved.

* Corresponding author. Sexual Medicine and Andrology, Biomedicine, University of Florence, Florence, Italy.

E-mail address: m.maggi@dfc.unifi.it (M. Maggi).
\end{abstract}




\section{Introduction}

Erectile dysfunction (ED) has emerged as an important marker of cardiovascular (CV) and overall health, independently of other known conventional risk factors [1]. Normal sexual activity throughout the adult lifespan has been associated with a reduced incidence of CV events, suggesting a protective role [2]. Coronary artery disease is preceded by ED in half of the affected subjects, underlining the need for proper screening [3]. Sexual dysfunction is the most specific symptom of late-onset hypogonadism ( $\mathrm{LOH})[4]$ in the aging man, a condition also associated with an increased mortality for CV events [5]. However, ED still remains largely underdiagnosed and untreated. The Global Study of Sexual Attitudes and Behavior showed that $<30 \%$ of men with ED had sought medical help, due to high social and personal barriers [6].

Public awareness of the benefits of phosphodiesterase type 5 inhibitors (PDE5-Is) has significantly shortened the time lag between the onset of ED and the seeking of medical help [7]. The same cannot be said for testosterone replacement therapy (TRT) in LOH, despite the availability of excellent multifaceted treatment options, due to the longstanding controversies surrounding safety versus efficacy in male sexual dysfunction. The scientific community is sharply divided into those for or against TRT, with a proliferation of studies with apparently contradictory findings, generating a debate without comparison in any other hormone deficiency.

These considerations prompted us to perform a critical appraisal of the major studies of TRT in sexual dysfunction, focusing on three of the critical questions: (1) Is TRT worthwhile in ED patients? If so, how and when? (2) Does testosterone ( $\mathrm{T}$ ) act centrally or peripherally? (3) What are the underlying facts and beliefs about the combination of $\mathrm{T}$ and PD5-I therapy? Is it safe?

\section{Evidence acquisition}

We reviewed the relevant medical literature, with a particular emphasis on original molecular studies, prospective observational data, and randomized controlled trials (RCTs) performed in past $20 \mathrm{yr}$ that included the search terms testosterone or hypogonadism and erectile function (EF). We provide a systematic review and critical appraisal of the data (see Supplement).

\section{Evidence synthesis}

\subsection{Hormonal assessment in erectile dysfunction patients}

The European Male Ageing Study (EMAS) found that 30\% of European men experienced ED and two-thirds of them were eugonadal [4]. In representative samples, the prevalence of hypogonadism ranges between $23 \%$ and $36 \%$ of ED subjects [8] and varies according to the cut-off value adopted for the diagnosis, respectively $7 \%, 23 \%, 33 \%$, or $47 \%$ for $\mathrm{T}$ levels of $<7,10.4,12$, or $14 \mathrm{nmol} / 1$ [9]. These figures, however, are simple associations that do not imply any causal association between the two conditions.

Detractors of universal screening of androgen deficiency in ED subjects point out that, in addition to the known causes of hypogonadism (Fig. 1), the frequent real or

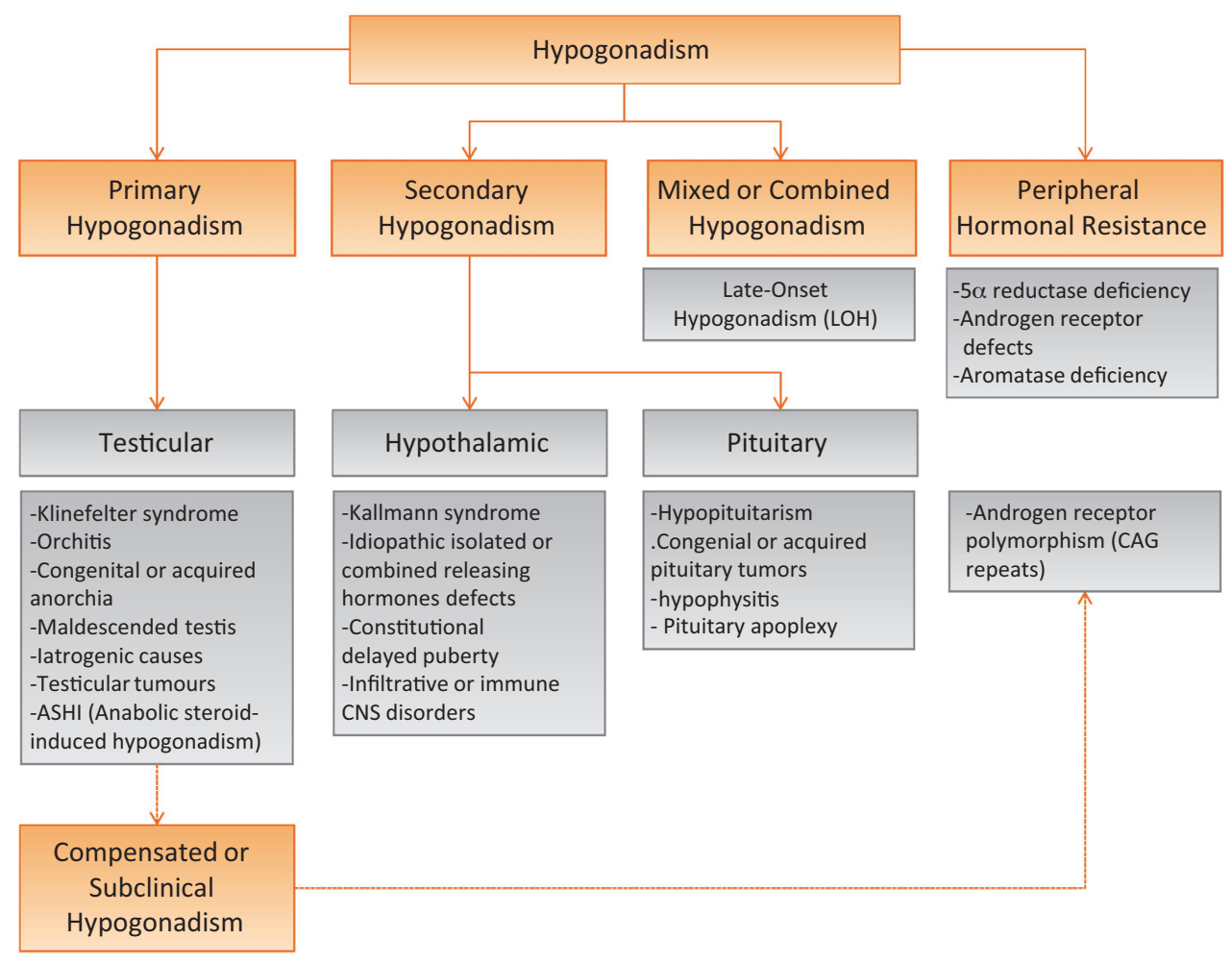

Fig. 1 - Causes of reduced androgen levels in men with erectile dysfunction. CNS = central nervous system. 
Table 1 - Checklist for the assessment of gonadal status in patients with erectile dysfunction

1. Check for hypoactive sexual desire, reduced frequency of nocturnal erections, or delayed ejaculation: All increase the likelihood to detect hypogonadism.

2. Use questionnaires/structured interviews: the Androsiedy, St. Louis University Androgen Deficiency in Aging Males, the Aging Male Scales, the Massachusetts Male Aging Study, and the European Male Ageing Study Sexual Function Questionnaire.

3. Measure prostate volume: A volume lower for age increases the likelihood of detecting hypogonadism.

4. Ask about seminal fluid: Low volume (hypoposia) may be a sign of hypogonadism.

5. Check T in morning: Blood samples should be obtained in a fasting state, between 8 AM and 11 PM.

6. Ask about sleeping: T measurement should be done after a good night's sleep.

7. Ask about alcohol abuse. Ask about drugs (see Supplemental Table 1).

8. Repeat T measurement: It is always good to confirm $T$ a couple of weeks later, together with the assessment of luteinizing hormone and prolactin.

9. Don't forget binding proteins: In obesity, metabolic syndrome, type 2 diabetes. or hyperthyroidism or if patients were currently treated with antiepileptic drugs, check for SHBG levels and calculate the fT according to the Vermeulen formula (http://www.issam.ch/freetesto.htm). A calculated free $\mathrm{T}<65 \mathrm{pg} / \mathrm{ml}$ is associated with ED [4].

10. The measurement of fT trough radioimmunoassay is unreliable, and it must not be evaluated.

$\mathrm{ED}=$ erectile dysfunction; $\mathrm{fT}=$ free testosterone; $\mathrm{SHBG}=$ sex hormone-binding globulin; $\mathrm{T}$ = testosterone

spurious fluctuations in $\mathrm{T}$ levels produce several false diagnoses. Drugs could also affect T levels (see Supplemental Table 1). A transient drop in T could be due to acute illness, and no lower limit of normal is universally accepted. There is, however, general agreement that total $\mathrm{T}>12 \mathrm{nmol} / \mathrm{l}$ (>350 ng/dl) does not require replacement therapy, whereas $\mathrm{T}<8 \mathrm{nmol} / \mathrm{l}$ does eventually merit treatment. The strength of this consensus is inversely proportional to the age of the subjects, so replacement therapy for a baseline $\mathrm{T}$ of $10 \mathrm{nmol} / \mathrm{l}$ would gain more support in a 40 -yr-old man than in a 70 -yr-old man. Table 1 provides suggestions on how to assess gonadal status in ED patients. A second confirmation of a reduced $T$ level is highly recommended, possibly including measurement of sex hormone-binding globulin (SHBG), to enable the calculation of free testosterone (fT) [10]. Prolactin should also be assessed in all cases of reduced $\mathrm{T}$ values [11].

Surprisingly, most guidelines do not consider the differential diagnosis of the cause of hypogonadism to be mandatory in the diagnosis of $\mathrm{LOH}$; as a consequence, luteinizing hormone ( $\mathrm{LH}$ ) measurement is often considered unnecessary $[10,12]$. This oddity is justified by the very high frequency of a mixed etiology, with an altered hypothalamic-pituitary-gonadal (HPG) feedback loop secondary to age, comorbidities, and drugs. Measuring LH could be useful not only for the diagnosis of primary hypogonadism (low $\mathrm{T}$ and elevated LH), often associated with sexual symptoms, but also to identify "compensated" or "subclinical" hypogonadism $[13,14]$.

The latter condition is characterized by normal or lownormal $\mathrm{T}$ (gray zone) and elevated LH ( $>9.4 \mathrm{U} / \mathrm{l}$ ). This subgroup of subjects, whose number steadily increases with age, is the largest in the elderly. In addition, young men with Klinefelter syndrome, the most common numerical chromosomal aberration ( $47, \mathrm{XXY}$ ), affecting $0.2 \%$ of the male population (www.uroweb.org/guidelines) [10], often have subclinical hypogonadism that later in life becomes overt primary hypogonadism [15]. The latter cannot be dismissed as "functional" and is not the consequence of acute illnesses. Like primary hypogonadism, it is strongly associated with physical and sexual symptoms, indicating that when $\mathrm{T}$ declines from a previously high-normal to a low-normal level, the high LH becomes a biomarker for insufficient androgenization. The finding of elevated $\mathrm{LH}$ thus reinforces the need to consider replacement therapy, although clinical trials in this subgroup are scarce, and the data on long-term follow-up are only recently emerging. Conversely, a very low $\mathrm{T}$ in the presence of normal/low $\mathrm{LH}$ may indicate a pituitary tumor, even with a normal prolactin, and requires pituitary imaging [11].

\subsection{Molecular evidence for testosterone dependency of penile structure, growth, and responsiveness}

It is generally accepted that androgens modulate erectile physiology in humans and animals. Although most of the animal data are derived from androgen ablation from surgical castration and gonadotropin-releasing hormone (GnRH) analogs, a model that can hardly be transferred to ED in humans, at least one study used, as an experimental model, hypogonadism induced by a high-fat diet, and the findings were consistent with the reports from castration studies [16]. Three levels are under T control: the central nervous system (CNS) nuclei, the spinal motoneurons, and the genital tissues (Fig. 2). The CNS effects of androgens are complex, mainly exerted on the release of stimulatory neurotransmitters such as dopamine, oxytocin, and nitric oxide (NO), controlling sexual dimorphic development and mating behaviors [17]. At peripheral levels, androgens modulate nearly every component involved in EF: structure, function, and innervation of trabecular smooth muscle cells, endothelial function of penile vessels, and fibroelastic properties of the corpus cavernosum. However, the molecular pathways involved are far from understood. In addition, part of the erectile response to $\mathrm{T}$ is centrally mediated, through an effect on sexual desire, and this dichotomy has split researchers, with some supporting a predominance of the central over the peripheral sites of action. Finally, animal studies have shown speciesspecific differences and were performed after castration, a model very different from hypogonadism in men, generating uncertainty that is further complicated by the paucity of available human data.

\subsubsection{The nitric oxide and adrenergic pathways}

Most animal studies agree that castration caused a rapid drop in intracavernous pressure due to both reduced arterial inflow and altered veno-occlusion during stimulated erections [18]. In rats, castration is associated with a 


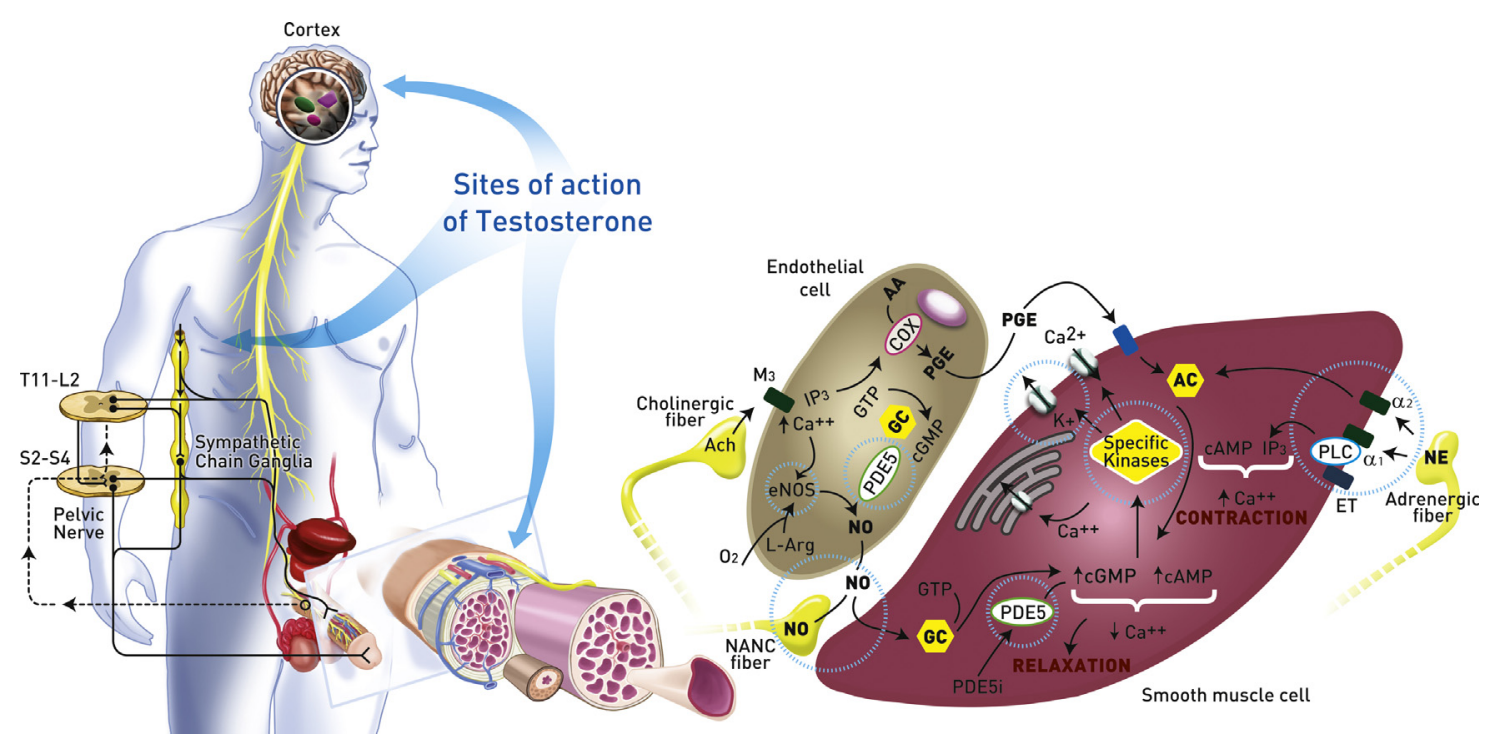

Fig. 2 - Sites of action of androgens in male sexual function. Blue arrows and dotted blue circles highlight the targets of testosterone. Ach = acetylcholine; $\mathrm{Ca}^{2+}=$ calcium; $\mathrm{cAMP}=$ cyclic adenosine monophosphate; cGMP = cyclic guanosine monophosphate; eNOS = endothelial nitric oxide synthase; ET = endothelin; GC = guanylate cyclase; $\mathbf{G T P}=$ guanosine triphosphate; $\mathrm{IP}_{3}=$ inositol triphosphate; $\mathrm{K}^{+}=$potassium; $\mathbf{N A N C}=$ nonadrenergicnoncholinergic; $\mathrm{NO}=$ nitric oxide; $\mathrm{PDE} 5$ = phosphodiesterase type 5; $\mathrm{PGE}=$ prostaglandin $\mathrm{E} ; \mathrm{AC}=$ adenylate cyclase; $\mathrm{NE}=$ norepinephrine; PLC $=$ phospholipase $C$.

rapid reduction in neuronal nitric oxide synthase (nNOS) activity [19] and pelvic ganglion activity [20]. This is almost completely reversed by NO, suggesting that NO generation is a major acute effector of androgens (Fig. 2). However, reports of nNOS response differ significantly, with some studies showing an increased activity in rats but no change in protein expression [19] and others showing no effect in rabbits [21]. Studies performed in L-NAME-treated animals (a nitric oxide synthase [NOS] inhibitor), revealed some additional mechanisms involved in the androgen regulation of EF. Interestingly, this NO-independent mechanism still appears to require cyclic guanosine monophosphate (cGMP) generation, critical to both NO-independent and NO-dependent pathways [22] Non-NO-mediated androgenic effects seem to be exerted mainly on the veno-occlusion mechanism.

Sensitivity to neurotransmitters is another possible target of androgens (Fig. 2). In rats, castration appears to increase the $\alpha_{1}$-adrenergic responsiveness of the cavernosal smooth muscle cells [23]. Surprisingly, in rabbits the $\alpha_{1}$-adrenergic receptors seem to be downregulated by castration and restored by androgen replacement [21]. Castration in rats is also associated with a decreased density of nonadrenergicnoncholinergic (NANC) innervating fibers and reduced NANC-mediated relaxation in isolated corpus cavernosum strips, but again, not in rabbits, confirming interspecies differences [21]. In summary, nNOS activity seems to be the major target of androgens $[19,20]$, followed by opposite regulation of NANC and $\alpha_{1}$-adrenergic signaling [21].

\subsubsection{The cyclic guanosine monophosphate-phosphodiesterase} type 5 pathway

A number of in vitro animal and human studies found that PDE5 expression in the penis is upregulated by androgens $[21,24,25]$. This finding generated a paradox because an increase in this enzyme should exert an inhibitory effect on penile tumescence. However, the latter observation fits well with various clinical observations, and the authors suggest that androgens play a dual role in the erectile process by controlling both pro-erectile and antierectile signaling pathways. This has also been claimed to explain the neutral effect of hypogonadism on human erections, as a net result of decreased cGMP generation (lower NO activity) accompanied by reduced cGMP degradation (lower PDE5 activity).

However, studies have questioned the androgenic regulation of PDE5 in the penis, suggesting that the lower levels observed after androgen deprivation are biased by the overall reduction in smooth muscle content [26]. Attempts to extrapolate data from different cell types and tissues, including prostate or Leydig cells, did not help resolve the question, with divergent effects ranging from null to up- or even downregulation of PDE5 by androgens [27]. For example, in the rabbit prostate, it was recently demonstrated that metabolic syndrome-induced low $\mathrm{T}$ is associated with an upregulation of PDE5 reversed by T supplementation [28]. Sustained cGMP levels are crucial for any androgenic effect on penile erection [22]; whether this is a direct $[21,24,25]$ or indirect $[27,28]$ mechanism remains controversial.

\subsubsection{Penile innervation and structure}

The data just presented suggest that a major effect of $\mathrm{T}$ is on the postganglionic parasympathetic neurons, or even further upstream, within the autonomic nervous system (Fig. 2). A more complex pelvic neuronal activity is supported by the fact that the effects of castration on penile hemodynamics, including NOS activity, can be transiently reversed in vivo by short-term electrical stimulation of the cavernosal nerve [19]. Most studies agree that castration produces changes in 
the critical balance between trabecular smooth muscle and connective tissue. Androgen deprivation results in programmed trabecular smooth muscle cell death (apoptosis) and an increase in the extracellular matrix [21]. Androgen deprivation is also associated with the accumulation of fatcontaining cells (fibroblasts or preadipocyte-like cells), especially in the subtunical region of the corpus cavernosum, thus contributing to impaired veno-occlusion [29]. According to the neuronal circuitry hypothesis, the main role of androgens is to support the adequate neuronal stimulation of the corpora cavernosa, also necessary to maintain tissue structural integrity and the differentiation of penile mesenchymal stem cells. The latter hypothesis is supported by the similarities between penile fibrotic changes developing after castration, in animals, and those after denervation following prostate surgery, in men.

In humans, $\mathrm{T}$ influences penile development, mainly as a result of extracellular stromal expansion [30]. Postnatal penile length and growth rate also seem to be correlated with the T surge occurring in the first 3 mo of life (mini-puberty) [31]. However, no further correlation is seen in postpubertal adults. Most studies agree that androgen sensitivity and androgen receptor expression vary with age and stage of penile development. Whether or not this mechanism is primarily regulated by androgens remains controversial. The few human studies failed to document this feedback, suggesting that penile growth cessation after puberty depends on other, nonandrogen-dependent mechanisms [30]. Thus androgens seem necessary to maintain the fibroelastic properties of penile tissues, at least in animal models [19,21,29]. Studies in humans suggest that androgens are also involved in prepubertal penile growth [30,31], although other independent mechanisms control growth cessation [30].

\subsection{4. $5 \alpha$-reductase inhibitors and erectile function}

Following a proliferation of studies in the 1990s, interest in androgen action in penile physiology gradually diminished. However, attention has been renewed by the discovery that a group of young subjects developed persistent diminished libido and ED as a consequence of early exposure to $5 \alpha$-reductase inhibitors (5-ARIs) [32]. This condition, termed postfinasteride syndrome, seemed to occur in a small, but not insignificant, subgroup of young subjects who had taken a 5-ARI for alopecia (although similar symptoms can also develop in patients taking a 5-ARI for benign prostatic hyperplasia). The severity of symptoms seems to correlate to an early intake at the end of pubertal development, at a stage when the effects of androgenic activity are still peaking. The 5-ARI transforms not only $\mathrm{T}$ but also other metabolites that can in turn be converted into a subclass of neuroactive steroids with distinct physiologic actions.

In animal models, 5-ARIs have been associated with reduced $\mathrm{EF}$, with marked structural and functional alterations in penile tissue contributing to penile fibrosis that is mainly exerted through a modulation of cholinergic and adrenergic sensitivity, with no apparent change in PDE-5 [33]. The depressive symptoms developed by 5-ARI users who experienced sexual dysfunction are consistent with former animal studies showing that androgenic regulation of sexual activity is partially controlled through a modulation of reflexes of social behaviors [34] that goes well beyond libido. It is also known that different androgen thresholds are necessary to activate copulatory behavior and penile reflexes in rats, which are significantly increased in animals prenatally exposed to alcohol, stress, or endocrine disruptors [35]. The hypothesis of a dynamic reset of central threshold values could explain, at least in part, the androgen insensitivity of aging men chronically exposed to drugs and diseases.

\subsection{Association between testosterone and erectile function in men}

Most animal studies suffer from a short observational period following castration and androgen administration, which may influence nerve and tissue remodeling. Conversely, most human studies are cross sectional and show divergent results. Some describe a significant association of androgens with various measures of EF [36,37]; others do not [38]. Most of the early studies were retrospective, underpowered, uncontrolled for comorbidities, body mass index, and SHBG, and weak on the methods used to assay hormones. The recent EMAS study, a sufficiently large prospective study using mass spectrometry, shed some light on this controversial issue [39]. The study found that total T is significantly associated with overall sexual function, and fT with ED and masturbation frequency, independently of $17-\beta$-estradiol $\left(E_{2}\right)$ or dihydrotestosterone. More importantly, it identified a cutoff of $8 \mathrm{nmol} / \mathrm{l}$ above which any further increase in circulating $\mathrm{T}$ lost any positive correlation.

These findings are in line with previous studies showing, in a human model of endogenous $\mathrm{T}$ suppression by $\mathrm{GnRH}$ agonists, a dose response consistent with the existence of a T threshold effect [40], and others showing that variation of $\mathrm{T}$ levels within the normal range had no effects on sexual function [41]. However, some authors have pointed out that hypogonadal men may have near-normal sexual activity [37]. Overall, dose-response studies seem to suggest that the androgen dependency of EF is maintained at threshold values far below those required to maintain the function of other target organs. This has been demonstrated in otherwise healthy men with low $\mathrm{T}$, but it does not automatically translate to elderly men with comorbidities, in whom these thresholds may be reset.

The EMAS study also showed that $\mathrm{E}_{2}$, but not $\mathrm{T}$, correlated with the psychological symptoms of male aging, confirming the findings of Basar et al. [42]; both these studies found a robust independent correlation between $E_{2}$ and sexual dysfunction-associated distress. Another study found that $\mathrm{T}$ was associated with somatized anxiety only in the older men with ED [36]. These aspects are most novel in light of the recently introduced concept of compensated or subclinical hypogonadism [13] (Fig. 1). In fact, subclinical hypogonadism is also strongly associated with physical and sexual symptoms, indicating that when $\mathrm{T}$ in men declines from a previously high-normal to a low-normal level, the 
high LH becomes a biomarker for insufficient androgenization $[13,14]$.

\subsection{Effects of treating erectile dysfunction in hypogonadal men using testosterone}

Normal men probably have more androgens than are necessary, in the short term, for normal sexual activity. Acute, complete androgen withdrawal is unequivocally associated with loss of sexual interest and erectile failure. These symptoms are promptly reversed by the administration of a small amount of $\mathrm{T}$. In the 1980s, Bancroft and $\mathrm{Wu}$ performed the pivotal studies to discriminate central versus peripheral effects, demonstrating that in acute settings, erectile capacity in response to visual stimulation is less sensitive to androgen than is sexual interest, fantasies, and cognitive sexual activities [43].

Several clinical trials documented a significant improvement in erections and sexual function in hypogonadal men [44-47]. Uniquely among hormone replacement studies, the non-placebo-controlled trials are often dismissed as not evidence based. The few available RCTs were reviewed in three distinct meta-analyses showing a large effect of TRT on libido in men with reduced androgen levels, and a small effect on sexual satisfaction and various parameters of EF in men with low to normal $\mathrm{T}$ levels $[8,48,49]$. The first one reports the positive effect of TRT on EF in men with mean T levels $<10 \mathrm{nmol} / \mathrm{l}$ (standardized mean difference [SMD]: 1.8; 95\% confidence interval [CI], 0.31-3.43) [48]. In a subsequent one, Bolona et al. [49] found a small yet significant effect (SMD: 0.34; $95 \% \mathrm{CI}, 0.03-0.65$ ) on EF of men with low-normal $\mathrm{T}$ levels, and a greater effect in the subgroup of young subjects (SMD: 1.80; 95\% CI, 1.0-2.7), emphasizing a role of aging as a possible moderator of ED responsiveness to TRT. In particular, a nonsignificant effect was found in older men. In the last available meta-analysis, Tserstvadze et al. [8] concluded that results of any TRT were inconsistent regarding their effects on $\mathrm{EF}$, degree of erection, or improved erection. Due to these contrasting results, we systematically analyzed all the data available so far concerning RCTs, reported in the Supplement (Supplemental Table 2).

The 20 identified RCTs showed large discrepancies in clinical response, with individual variations related to bias in the studies, age, type, and potency of T preparation, outcome measures, and comorbidities of the recruited subjects. No effect was found in men with $\mathrm{T}>12 \mathrm{nmol} / \mathrm{l}$, whereas in 10 of the 14 RCTs performed in hypogonadal men, a beneficial effect of TRT on EF was found. Among studies providing crude International Index of Erectile Function (IIEF) data [45,46, 50-53], TRT produced a weighted mean improvement of baseline IIEF score of 39\% (range: $22-79 \%$ ) corresponding to a weighted mean delta of IIEF- 5 of $4.32 \pm 2.01$ points (range: 3-8). The European Association of Urology (EAU) guidelines for male sexual dysfunction gave a level of evidence (LE) of $1 \mathrm{~b}$ (at least one RCT) and a grade of recommendation (GR) of B (based on well-conducted but not randomized trials) to the need to treat at first any "curable cause of ED" including hypogonadism [12]. The EAU guidelines on hypogonadism gave an LE of 3 (based on well-designed and nonexperimental studies) and a
GR of B the opportunity to treat "decreased libido and erection" with testosterone [10].

Another relevant aspect that has only recently received attention is the time course of $T$ effects (ie, the length of treatment necessary to achieve the maximum result). A systematic analysis showed effects on libido, ejaculation, and sexual activity within just 2-3 wk, whereas effects on EF may require up to 6 mo to become detectable by IIEF [54]. Recent RCTs showed that a statistically significant improvement in IIEF, detectable at $6 \mathrm{mo}$ as marginal changes $[46,47]$, can achieve a further significant increase after $12 \mathrm{mo}$ of an open-label treatment [45,46]. Taken into account these limitations, the time course of TRT has been claimed to explain some negative findings in the experimental human studies on $\mathrm{T} / \mathrm{sex}$ thresholds that were mainly performed in the acute settings (weeks), as opposed to penile tissue recovery that may require several months.

Few studies have explored whether there is any difference between raising $\mathrm{T}$ by exogenous steroid administration or by Leydig cell stimulation. This is more relevant in view of the increasing proportion of aging men with ED who still wish to achieve fatherhood. Buvat showed that raising $\mathrm{T}$ by human chorionic gonadotropin (hCG) is associated with an increase in sexual activity in half of men with normal baseline T levels [55].

Guay [56] showed that the normalization of androgens by clomiphene produced a satisfactory response in 39\% of all treated men, with younger subjects $(<55 \mathrm{yr})$ responding better than older men and men with comorbidities. One of the most interesting findings was that pituitary stimulation in secondary hypogonadism, even if related to acute or chronic illness, can be used transiently while the underlying problem is corrected. In addition, a recent study showed that clomiphene citrate is also safe and effective for the long-term management of male hypogonadism [57], making it suitable for men seeking fertility. Alternatively, the adjunct of low-dose hCG to TRT prevents spermatogenesis suppression and can be used in impotent hypogonadal men in whom fertility remains an issue [58] (Fig. 3).

To summarize, increasing androgen levels, either by hormonal replacement [8;45-53] (Supplemental Table 2 ) or by the stimulation of Leydig cells [55-57] is superior to placebo in improving various sexual outcomes, but the magnitude and timing of effects $[45,46,54]$ are highly variable and difficult to predict. To improve the response, a combined treatment could also be considered (Fig. 3). On the contrary, when baseline $\mathrm{T}$ levels are normal, no beneficial effects has to be expected from TRT.

\subsection{Effects of treating erectile dysfunction in hypogonadal men using a phosphodiesterase type 5 inhibitor}

PDE5-Is are rapid and potent drugs acting directly on the mechanisms of erection, and they have changed the expectation of both physicians and patients about how to improve EF. The fact that sexual activity per se can affect T levels has been hypothesized since the 1970s. However, the first formal studies by Jannini and colleagues showed that restoring EF by nonhormonal therapies (eg, psychotherapy, 


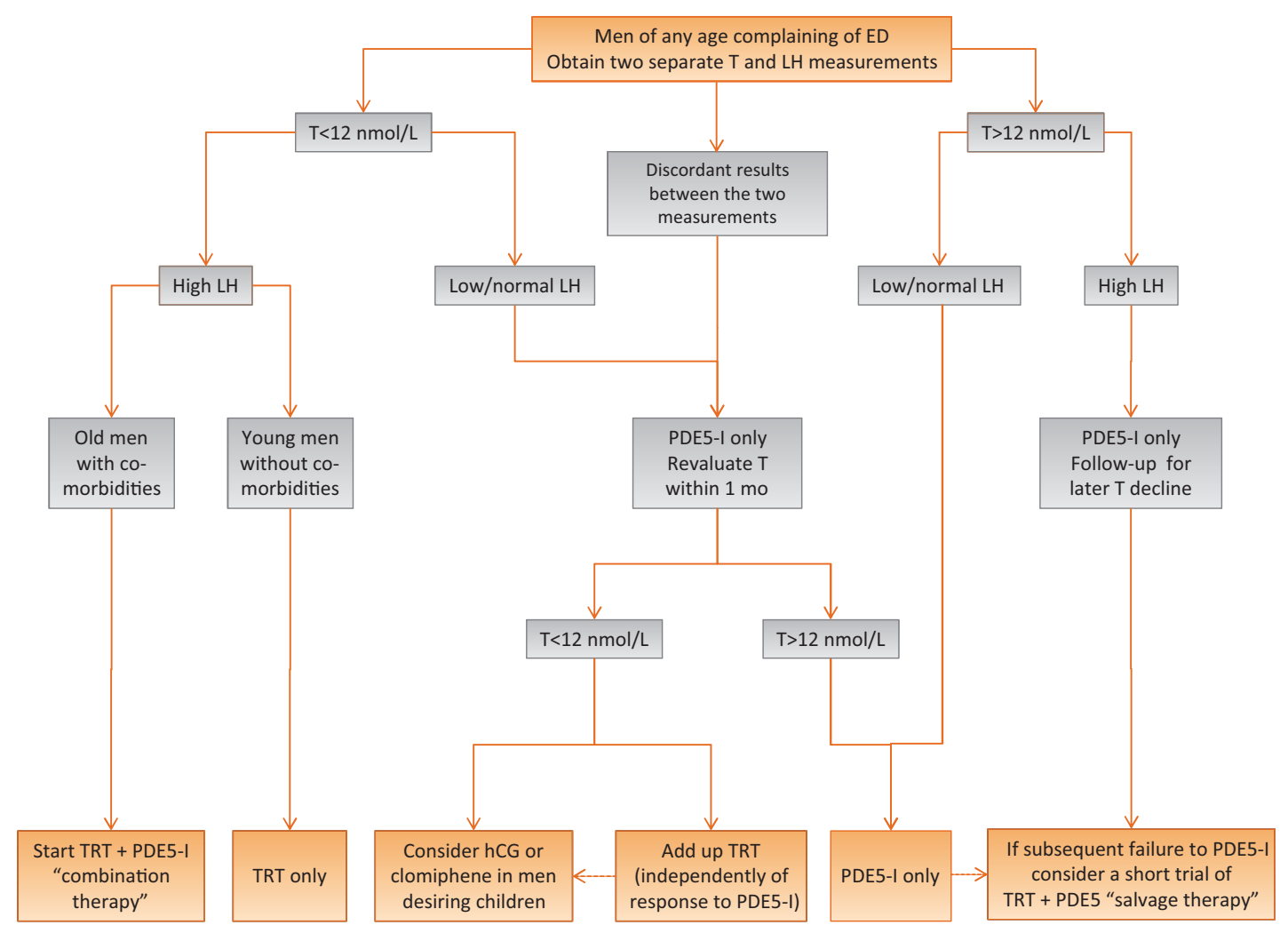

Fig. 3 - Pathophysiology-oriented algorithm for the treatment of erectile dysfunction in men with altered circulating testosterone levels. ED $=$ erectile dysfunction; hCG = human chorionic gonadotropin; LH = luteinizing hormone; PDE5-I = phosphodiesterase type 5 inhibitor; T = testosterone; TRT = testosterone replacement therapy.

intracavernous injections) in various settings can raise circulating $\mathrm{T}$ by $30-40 \%$ of baseline values [59]. The same effect was subsequently demonstrated with PDE5-I therapy [60]. An attempt was made to investigate whether this was a drug-specific effect. However, the increase in the frequency of sexual intercourse, by whatever means this was achieved, was the best predictor of androgen recovery $[59,60]$. This finding was confirmed in a large RCT, which found that a 4-wk run-in of PDE5-I in hypogonadal men significantly raised $\mathrm{T}$ levels by a mean of $4 \mathrm{nmol} / \mathrm{l}$ [61].

The consequences of being unable to achieve full penetration are thought to be the major cause for downregulation of the neurohormonal mechanism that controls the GnRH pulse generator and in such patients causes hypogonadism [13]. However, recent studies show that PDE5 is expressed by Leydig cells and its inhibition can increase hormone release [27], suggesting that a direct testicular action is also possible. Based on the available studies, the increase in $\mathrm{T}$ that can be expected after PDE5-I use is in the range of $3-6 \mathrm{nmol} / 1[59,61]$. These data support a possible role of PDE5-I as the sole treatment in selected men presenting with ED and reduced T levels (Fig. 3). However, the use of only a PDE5-I may be insufficient in other cases: A young man with severe hypotestosteronemia is unlikely to restore eugonadism simply by increasing his sexual performances with a PDE5-I. In addition, given the proposed mechanisms, subjects with an elevated LH are unlikely to respond to a PDE5-I, given that the feedback is already enhanced and Leydig cells might be dysfunctional.

\subsection{Effects of combining testosterone and phosphodiesterase type 5 inhibitor}

Combination therapy with PDE5-I and T is highly debated, with strong reasons in favor or against it asserted by the various researchers. PDE5-Is are effective, but regardless of their pharmacokinetics or the regimen used, none have been shown to cure ED. Thus they remain symptomatic drugs [60]. In hypogonadal men, PDE5-Is alone might be sufficient to improve erections, but they are inadequate to address all domains of sexual function and the systemic complication of hypogonadism (Fig. 3). Epidemiologic studies show that sexual dysfunction is one of the main symptoms causing hypogonadal men to seek medical help [4]. For this reason, once treated with PDE5-Is, they may no longer be interested in correcting their underlying androgen deficiency. Symptomatic pro-erectile treatment will thus leave such men otherwise untreated and exposed to a greater risk of osteoporosis, diabetes, dyslipidemia, obesity, and CV morbidity and mortality [62].

Although PDE5-I may effectively treat erections, as measured by the IIEF, they cannot address the ancillary sexual signs and symptoms associated with hypogonadism, such as low libido, reduced ejaculatory volume, and other 
symptoms [63]. Therefore, even if erection hardness is tangibly improved, the subject's sex life may not be fully restored.

3.6.1. Testosterone replacement therapy and phosphodiesterase type 5 inhibitor: "salvage" versus "combination" therapy

The fact that ED and hypogonadism often coexist in aging men led some authors to explore whether the combination of a PDE5-I and TRT would elicit beneficial effects. Originally proposed as "salvage therapy" for nonresponders or PDE5-I failures [64,65], this approach has been improperly transformed into a "combination" therapy, with the aim of adding the beneficial effects of each drug on EF to one another. The post hoc analysis of the TADTEST trial showed that below a threshold of $10.4 \mathrm{nmol} / \mathrm{l}(300 \mathrm{ng} / \mathrm{dl}$ ) for total T, the efficacy of PDE5-I is suboptimal [65]. The salvage rate that could be obtained in hypogonadal men, failing a PDE5-I, was highly variable ranging from $32 \%$ to $100 \%$ [66], with some sort of improvement expected in about twothirds of treated patients.

However, this approach was recently questioned by a large study from Spitzer and colleagues, designed to address whether TRT has any additional effect when erection score is maximized by a PDE5-I [61]. The study definitively confirmed that there is no need to add $\mathrm{T}$ when $\mathrm{EF}$ is already being restored by a PDE5-I, other than to treat the systemic complications of hypogonadism. However, the trial was not powered to address any role of $\mathrm{T}$ as a salvage therapy because there was a significant increase in $\mathrm{T}$ during the sildenafil optimization run-in. This resulted in a large percentage of the study subjects with $\mathrm{T}>12 \mathrm{nmol} / \mathrm{l}$ at randomization, and the overall number of PDE5-I failures was low.

Whether or not TRT should be offered to all men who remain hypogonadal while failing PDE5-I therapy remains debated (Fig. 3). TRT might rescue some of these failures by boosting all aspects of men's sexual health, including several minor targets, from libido to ejaculation volume and the so-called nonspecific mood-lifting properties. Putative benefits are unlikely to be exerted through an increase in erection hardness, the parameter scored by the IIEF-5, but rather by subtle changes in cavernous smooth muscle cells, libido, motivation, and ejaculation [63] that may also be important, even if not measured by the IIEF. In summary, TRT should be used first in some subgroups of patients, especially in young men with organic hypogonadism, whereas others may benefit from the use of combination therapy from the beginning (Fig. 3). Yet a relevant group of ED hypogonadal patients could safely be started on PDE5-I monotherapy and, in those who retain persistently low T levels, TRT should be offered as a salvage therapy for PDE5-I failure (Fig. 3).

\subsection{How and when to increase testosterone levels in erectile dysfunction patients}

If the cause of ED is low T, as is often the case in young hypogonadal men, androgen replacement is the cure, and monotherapy often suffices. This can be achieved with the daily administration of any of the several available topical formulations (Table 2). The cutaneous side effects of the latest gels and solutions are insignificant, although they are more common with older patches. Treatment of severe hypogonadism in younger men might require higher doses than those delivered by the standard gel sachets (usually $50 \mathrm{mg}$ ). $\mathrm{T}$ monitoring is thus highly recommended to achieve the desired level. Formulations in adjustable dispensers are more suitable for dose titration [67]. The recently introduced long-acting $\mathrm{T}$ (available in Europe) overcomes the compliance problems associated with daily administration, offering a treatment that is particularly suitable for young men [47]. Administration once every 12-14 wk frees the patient from considering himself abnormal as a daily application would inevitably recall. It also avoids the problems of washing off the gel or the skin irritations associated with sweating of more physically active men. Long-acting $\mathrm{T}$ undecanoate injections have been reported as safe and reliable in both young and older subjects [47], but given the uncertainty of the diagnosis, the variability of $\mathrm{T}$ measurement, and the unpredictable hematocrit response, it is advisable to first use a 3-mo run-in with a short-acting gel. For men who intend to father children, a number of alternative options are available including clomiphene or $\beta$-hCG (Fig. 3).

When ED is not due solely to hypogonadism but also to a concomitant vascular or metabolic disorder, TRT alone is insufficient to restore erection, and PDE5-I use is required. The effects of androgens on erection are in fact slow and progressive $[45,46]$, and they are often imperceptible to the patient if not administered over a long time [54]. Young hypogonadal men in a stable relationship are often eager to wait and see if the effects of testosterone "cure" their erection while benefiting from the spurt in libido, rather than immediately starting a PDE5-I, perceived as a drug for older men. However, those who experience repeated failures or have an unstable relationship may ask for a drug enabling their rapid achievement of erection, thus counteracting their performance anxiety. Cost is another issue. Although considered very safe, TRT requires periodical monitoring of blood parameters (Table 3 ). This adds to the cost of the $\mathrm{T}$ and any PDE5-I. At least hematocrit and prostate-specific antigen (PSA) in addition to $\mathrm{T}$ are generally performed at least every 6 mo [10]. One aspect that deserves mention is the issue of the polymorphism of androgen receptor, in particular the length of CAG repeats that affect the efficiency of receptor signaling that account for a significant variability in the thresholds of symptoms and, more importantly, the responsiveness to TRT (see Supplement) [68].

\subsection{Proposal of a treatment algorithm}

The collected evidence shows that TRT monotherapy restores sexual function in some cases, whereas in others a PDE5-I only improves $\mathrm{T}$ levels. The combination of a PDE5-I and TRT has been tested in hypogonadal men not responding to androgens or in those with persistent hypogonadism following PDE5-I failure. A critical appraisal 
Table 2 - Available preparations to treat male hypogonadism

\begin{tabular}{|c|c|c|c|}
\hline Compound & Dosage & Advantages & Disadvantages \\
\hline \multicolumn{4}{|l|}{ Oral agents } \\
\hline T undecanoate & $\begin{array}{l}120-240 \mathrm{mg} \\
2-3 \text { times daily }\end{array}$ & $\begin{array}{l}\text {-Oral } \\
\text {-Adjustable dose }\end{array}$ & $\begin{array}{l}\text {-Variable } \mathrm{T} \text { levels and clinical responses } \\
\text {-Must be taken with meals containing at least } 20 \mathrm{~g} \text { of lipids }\end{array}$ \\
\hline \multicolumn{4}{|l|}{ Intramuscular agents } \\
\hline Testosterone enanthate & $\begin{array}{l}250 \mathrm{mg} \text { every } \\
2-3 \mathrm{wk}\end{array}$ & -Low cost & $\begin{array}{l}\text {-Wide fluctuations in T levels } \\
\text {-Multiple injections } \\
\text {-Relative higher risk of polycythemias }\end{array}$ \\
\hline Testosterone cypionate & $\begin{array}{l}200 \mathrm{mg} \text { every } \\
2-3 \mathrm{wk}\end{array}$ & -Low cost & $\begin{array}{l}\text {-Wide fluctuations in T levels } \\
\text {-Multiple injections } \\
\text {-Relative higher risk of polycythemia }\end{array}$ \\
\hline T propionate & $\begin{array}{l}100 \text { mg every } \\
2 \mathrm{~d}\end{array}$ & -Low cost & $\begin{array}{l}\text {-Wide fluctuations in T levels } \\
\text {-Multiple injections } \\
\text {-Relative higher risk of polycythemias }\end{array}$ \\
\hline $\mathrm{T}$ undecanoate in castor oil & $\begin{array}{l}1000 \mathrm{mg} \text { every } \\
10-14 \mathrm{wk}\end{array}$ & $\begin{array}{l}\text {-Efficient T normalization } \\
\text {-Long lasting } \\
\text {-Better compliance }\end{array}$ & $\begin{array}{l}\text {-Pain at injection site } \\
\text {-Requires injection training }\end{array}$ \\
\hline \multicolumn{4}{|l|}{ Subcutaneous agents } \\
\hline Surgical implants & $\begin{array}{l}4 / 6200-\mathrm{mg} \text { implants } \\
\text { lasting up to } 6 \text { mo }\end{array}$ & -Treatment only twice per year & $\begin{array}{l}\text {-Placement is invasive } \\
\text {-Risk of extrusion and site infections } \\
\text {-Requires trained operator }\end{array}$ \\
\hline \multicolumn{4}{|c|}{ Controlled release $\mathrm{T}$ buccal formulation agents } \\
\hline $\mathrm{T}$ buccal & $30 \mathrm{mg} 2$ times daily & -Oral & $\begin{array}{l}\text {-Possible oral irritation } \\
\text {-Twice-daily dosing } \\
\text {-Unpleasant taste }\end{array}$ \\
\hline \multicolumn{4}{|l|}{ Transdermal agents } \\
\hline $\mathrm{T}$ patches & $\begin{array}{l}5-10 \mathrm{mg} \\
1 \text { daily }\end{array}$ & $\begin{array}{l}\text {-Mimics circadian rhythm } \\
\text {-Simple administration }\end{array}$ & $\begin{array}{l}\text {-Skin irritation } \\
\text {-Daily administration } \\
\text {-Noisy/sport/washing issues }\end{array}$ \\
\hline $\begin{array}{l}\text { T gel } \\
1-2 \%\end{array}$ & $\begin{array}{l}40-80 \mathrm{mg} \\
1 \text { daily }\end{array}$ & $\begin{array}{l}\text {-Efficient T normalization } \\
\text {-Flexible doses } \\
\text {-Less skin irritation }\end{array}$ & $\begin{array}{l}\text {-Possible transfer during intimate contact } \\
\text {-Daily administration }\end{array}$ \\
\hline $\begin{array}{l}\text { Underarm testosterone } \\
2 \% \text { solution }\end{array}$ & $\begin{array}{l}60-120 \mathrm{mg} \\
1 \text { daily }\end{array}$ & -Efficient T normalization & $\begin{array}{l}\text {-Possible transfer during intimate contact } \\
\text {-Daily administration }\end{array}$ \\
\hline $\begin{array}{l}\text { T gel } \\
1.62 \%\end{array}$ & $\begin{array}{l}20.25-81 \mathrm{mg} \\
1 \text { daily }\end{array}$ & $\begin{array}{l}\text {-Efficient T normalization } \\
\text {-Flexible doses } \\
\text {-Less skin irritation } \\
\text {-Lower amount to apply }\end{array}$ & $\begin{array}{l}\text {-Possible transfer during intimate contact } \\
\text {-Daily administration }\end{array}$ \\
\hline
\end{tabular}

reveals that the discrepancies among studies are related to inclusion criteria and outcome measures. TRT monotherapy, PDE5-I only, and the combination of the two could all be valid options for different cases of ED coexisting with hypogonadism. To support physicians in the selection of the best treatment strategy, we have developed a multistep treatment algorithm presented in Figure 3.

Table 3 - Safety monitoring during testosterone replacement therapy

\begin{tabular}{|c|c|c|c|c|}
\hline & Baseline & $3-6 \mathrm{mo}$ & $12 \mathrm{mo}$ & $\begin{array}{l}\text { Subsequent } \\
\text { screening } \\
\text { periodicity }\end{array}$ \\
\hline Testosterone & + & + & & $6-12 \mathrm{mo}$ \\
\hline LH/FSH/PRL & + & & & - \\
\hline Hematocrit/Hemoglobin & + & + & + & $6-12 \mathrm{mo}$ \\
\hline Glycemia/Lipid profile & + & & + & $12 \mathrm{mo}$ \\
\hline PSA & + & + & & 6-12 mo \\
\hline DRE & + & + & + & $12 \mathrm{mo}$ \\
\hline Bone densitometry scan & + & & & $24 \mathrm{mo}$ \\
\hline
\end{tabular}

DRE = digital rectal examination; $\mathrm{FSH}=$ follicular stimulating hormone; $\mathrm{LH}=$ luteinizing hormone; $\mathrm{PRL}=$ prolactin; $\mathrm{PSA}=$ prostate-specific antigen .

\subsection{Safety issues and future perspectives}

The controversies surrounding TRT for ED have been magnified by uncertainty on its safety. The two major concerns are the prostate and the CV system. The mistake of translating the effects of androgen deprivation in advanced prostate cancer (PCa) to the effects of androgen replacement in noncancerous prostate diseases has generated a number of unjustified fears. The saturation model proposed by Morgentaler and Traish [69] finally reconciled both ends of androgen's effects on prostate growth. A survey of most cited guidelines from international societies is reported in Table 4; all statements offer reassurances on the prostate safety of TRT, once contraindications, counseling, and required screening are respected. A collaborative study comparing 3886 men with incidental PCa with 6438 controls from 18 studies concluded that endogenous concentrations of sex hormones are not associated with the risk of PCa [70]. In contrast, growing evidence indicates that androgens exert an anti-inflammatory effect on human prostatic stromal cells. This could be useful in the treatment of lower urinary tract symptoms, possibly in combination with a PDE5-I [28;71]. 
Table 4 - Survey of currently available guidelines, recommendation, and statements addressing prostate safety of testosterone replacement therapy

\begin{tabular}{|c|c|c|c|c|c|}
\hline Target population & Issuing society & Year & Statement & $\begin{array}{l}\text { Level of } \\
\text { evidence }\end{array}$ & $\begin{array}{l}\text { Grade of } \\
\text { recommendation }\end{array}$ \\
\hline \multicolumn{6}{|c|}{ Risk of newly developed prostate cancer } \\
\hline Testosterone deficiency & ISSM [79] & 2013 & $\begin{array}{l}\text { There is no compelling evidence that high baseline } \\
\text { endogenous androgens or TRT cause prostate cancer or } \\
\text { prostate cancer progression in the noncastrated man. }\end{array}$ & $1 \mathrm{a}$ & - \\
\hline Male Hypogonadism & EAU [80] & 2012 & $\begin{array}{l}\text { Randomized controlled trials support the hypothesis } \\
\text { that TRT does not result in changes in prostatic } \\
\text { histology. }\end{array}$ & $1 b$ & - \\
\hline Late-onset hypogonadism & $\begin{array}{l}\text { ISA, ISSAM, } \\
\text { EAU, EAA, ASA [10] }\end{array}$ & 2009 & $\begin{array}{l}\text { At the present time, there is no conclusive evidence } \\
\text { that TRT increases the risk of prostate cancer or BPH. } \\
\text { There is also no evidence that T treatment will convert } \\
\text { subclinical prostate cancer to clinically detectable } \\
\text { prostate cancer. }\end{array}$ & 4 & C \\
\hline \multicolumn{6}{|c|}{ Patients with locally advanced prostate cancer } \\
\hline Testosterone deficiency & ISSM [79] & 2013 & $\begin{array}{l}\mathrm{T} \text { therapy is contraindicated in men with clinical } \\
\text { evidence of prostate cancer or any prostatic } \\
\text { abnormality suspicious of cancer until more evidence } \\
\text { of safety is available. }\end{array}$ & 5 & c \\
\hline Male hypogonadism & Endocrine Society [81] & 2010 & $\begin{array}{l}\text { We recommend against } \mathrm{T} \text { therapy in patients with } \\
\text { prostate cancer. }\end{array}$ & Low & Strong \\
\hline Late-onset hypogonadism & $\begin{array}{l}\text { ISA, ISSAM, } \\
\text { EAU, EAA, ASA [10] }\end{array}$ & 2009 & $\begin{array}{l}\text { There is evidence that } \mathrm{T} \text { can stimulate growth and } \\
\text { aggravate symptoms in men with locally advanced and } \\
\text { metastatic prostate cancer. }\end{array}$ & $2 a$ & A \\
\hline \multicolumn{6}{|c|}{ Patients successfully treated for localized prostate cancer } \\
\hline Testosterone deficiency & ISSM [79] & 2013 & $\begin{array}{l}\text { Men successfully treated for prostate cancer and } \\
\text { experiencing confirmed, very symptomatic T deficiency } \\
\text { may be candidates for TRT, after a prudent interval } \\
\text { (depending on the type of cancer treatment), if there is } \\
\text { no evidence of residual disease, and if they had an } \\
\text { initial tumor contained in the prostate gland that was } \\
\text { not high-grade Gleason score. } \\
\text { The risks and benefits must be clearly understood by } \\
\text { the patient, and the follow-up must be particularly } \\
\text { careful. Informed consent must be obtained. Safety data } \\
\text { are limited. }\end{array}$ & 4 & C \\
\hline Male hypogonadism & EAU [80] & 2012 & $\begin{array}{l}\text { In patients operated on for localized prostate cancer, } \\
\text { TRT should not start before } 1 \mathrm{yr} \text { of follow-up without } \\
\text { PSA recurrence has been completed. }\end{array}$ & 4 & B \\
\hline Late-onset hypogonadism & $\begin{array}{l}\text { ISA, ISSAM, } \\
\text { EAU, EAA, ASA [10] }\end{array}$ & 2009 & $\begin{array}{l}\text { Men successfully treated for prostate cancer and } \\
\text { experiencing confirmed symptomatic hypogonadism } \\
\text { are potential candidates for TRT after a prudent interval } \\
\text { if there is no clinical or laboratory evidence of residual } \\
\text { cancer. The risk and benefits must be clearly discussed } \\
\text { with and understood by the patient, and the follow-up } \\
\text { must be particularly careful. }\end{array}$ & $2 b$ & C \\
\hline \multicolumn{6}{|c|}{ Patients with severe LUTS due to BPH } \\
\hline Testosterone deficiency & ISSM [79] & 2013 & $\begin{array}{l}\text { Men with severe symptoms of bladder outlet } \\
\text { obstruction should not be started on TRT without prior } \\
\text { improvement of the comorbid condition. }\end{array}$ & 5 & C \\
\hline Male hypogonadism & Endocrine Society [81] & 2010 & $\begin{array}{l}\text { We recommend against TRT in patients with severe } \\
\text { lower urinary tract symptoms (IPSS }>19 \text { ) }\end{array}$ & Very low & Weak \\
\hline Late-onset hypogonadism & $\begin{array}{l}\text { ISA, ISSAM, EAU, } \\
\text { EAA, ASA [10] }\end{array}$ & 2009 & $\begin{array}{l}\text { Severe symptoms of LUTS evident by a high IPSS ( }>21) \\
\text { due to BPH represent a relative contraindication (there } \\
\text { are no compelling data to suggest that TRT causes } \\
\text { exacerbation of LUTS or promotes acute urinary } \\
\text { retention). After successful treatment of lower urinary } \\
\text { tract obstruction, this contraindication is no longer } \\
\text { applicable. }\end{array}$ & 4 & C \\
\hline \multicolumn{6}{|c|}{$\begin{array}{l}\text { ASA = American Society of Andrology; BPH = benign prostatic hyperplasia; EAA = European Academy of Andrology; EAU = European Association of Urology; } \\
\text { IPSS = International Prostate Symptom Score; ISA = International Society of Andrology; ISSAM = International Society for the Study of Aging Male; } \\
\text { ISSM = International Society for Sexual Medicine; LUTS = lower urinary tract symptoms; PSA = prostate-specific antigen; T = testosterone; TRT = testosterone } \\
\text { replacement therapy. } \\
1 \mathrm{a}=\text { evidence obtained from meta-analysis of randomized trials; } 1 \mathrm{~b} / 2 \mathrm{a}=\text { evidence obtained from at least one randomized trial. } 4=\text { evidence obtained from } \\
\text { expert committee reports or opinions or clinical experience of respected authorities. A = based on clinical studies of good quality and consistency addressing } \\
\text { the specific recommendations and including at least one randomized trial; } \mathrm{B}=\text { based on well-conducted clinical studies, but without randomized clinical trials; } \\
\mathrm{C}=\text { made despite the absence of directly applicable clinical studies of good quality. }\end{array}$} \\
\hline
\end{tabular}


3.9.1. Testosterone replacement therapy after successful treatment for prostate cancer

ED is a frequent complication of treatment for PCa. A current debate is whether men who have been surgically treated for localized PCa, without evidence of active disease and showing symptoms of $\mathrm{T}$ deficiency, can be considered for TRT. The EAU guidelines conclude that "there is limited evidence suggesting that such treatment may not pose an undue risk of prostate cancer (PC) recurrence or progression." Yet only scarce data are available.

For this reason, we performed a systematic review of published reports (Supplemental Table 3). Among a total of 179 men treated with TRT after radical prostatectomy, only 4 developed a biochemical recurrence (2.2\%) within $2 \mathrm{yr}$ of TRT (only $1.1 \%$ had a PSA elevation $>0.2 \mathrm{ng} / \mathrm{ml}$ ). Men treated with different modalities, other than radical prostatectomy, showed a higher recurrence rate. Although a statistically significant increase in PSA can been seen in TRT-treated men, independently of risk stratification, in most cases such an increase was not supportive of PCa recurrence. Multivariate analysis revealed that a higher baseline PSA level was the most relevant risk factor for disease progression, whereas Gleason grade, duration of TRT, and level of T achieved during TRT were not prognostic factors. A small consistent beneficial response on EF is reported in the few studies investigating this issue. A larger number reported improvement in energy, mood, and libido. However, the retrospective nature of these reports and the lack of placebo control limit their value.

3.9.2. Testosterone replacement therapy, phosphodiesterase type 5, and the cardiovascular system

Regarding CV safety, although a single study reports increased CV events in elderly men with limited mobility [72], meta-analyses on TRT for ED showed no increased CV risk $[48,49]$. Similarly, two other meta-analyses on TRT given for reasons other than ED found no significant effect with respect to specific CV outcomes: arrhythmia, coronary bypass surgery, myocardial infarction, and heart failure [73,74]. However, a more recent meta-analysis [75] found a statistically significant increase in "composite" CV-related event (odds ratio: $1.54 ; 95 \% \mathrm{CI}, 1.09-2.18$ ), as observed in the Testosterone in Older Men trial [72]. These data suggest that TRT is not entirely risk free in older men with a higher composite risk of CV events. In this respect, the increase in hematocrit remains the most significant identified change with an impact on the CV system. These safety warnings contrast with several studies showing that androgens can counteract the features of metabolic syndrome [5], thus determining a considerable reduction in CV risk [62,76]. However, the CV abnormalities seen in hypogonadal men with Klinefelter syndrome (ie, left ventricular diastolic dysfunction) are not entirely reversed by TRT. This suggests that delayed or suboptimal TRT can produce irreversible changes [77] or, alternatively, that cardiac dysfunction is independent of hypogonadism. The need for prompt treatment of the CV abnormalities associated with ED and hypogonadism was demonstrated by Montorsi et al., who found that severe ED precedes coronary artery disease by about $2-3$ yr [3]. Finally, recent studies demonstrated that chronic PDE5-I could also be beneficial to counteract cardiac remodeling [78] and lower urinary tract symptoms [71], showing that treating ED could have potential beneficial effects on various organs and systems.

\section{Conclusions}

All subjects with an organic cause of primary or secondary hypogonadism, especially if young and with a significant drop in T levels, should receive TRT as first-line treatment. Restoration of sleeping/morning erections should be monitored and, if necessary, PDE5-I added. In adults with LOH or any psychological distress, comorbidity, or drugrelated marginally reduced $\mathrm{T}$ level, a PDE5-I should be administered first in the attempt to restore sexual function, medications affecting sexuality should be discontinued where possible, and finally, but most importantly, any underlying conditions should be treated. Only then, if androgens remain low, should TRT be used in combination therapy (Fig. 3). This three-step approach, depicted in the algorithm, protects against an inappropriate use of these treatments. The EF improvement that can be expected using TRT is small, compared with a PDE5-I, and it may require several months, whereas the composite effects on various sexual domains, including libido, are greater especially in younger men. Based on the current evidence, there are no major safety concerns that limit the use of TRT in middle-age patients benefiting from treatment, not only in terms of sexual life, but also on the several systemic targets of the action of androgens, such as metabolism, bone and musculature. In older men with proven CV risks, TRT could yield to an increased number of adverse effects, and for this reason treatment should be individually tailored. The $21 \mathrm{st}$ century approach to sexual dysfunction must be based on the perspective of men's health as a whole.

Author contributions: Mario Maggi had full access to all the data in the study and takes responsibility for the integrity of the data and the accuracy of the data analysis.

Study concept and design: Isidori, Buvat, Corona, Goldstein, Jannini, Lenzi, Porst, Salonia, Traish, Maggi.

Acquisition of data: Isidori, Corona.

Analysis and interpretation of data: Isidori, Buvat, Corona, Goldstein, Jannini, Lenzi, Porst, Salonia, Traish, Maggi.

Drafting of the manuscript: Isidori, Maggi.

Critical revision of the manuscript for important intellectual content: Isidori, Buvat, Corona, Goldstein, Jannini, Lenzi, Porst, Salonia, Traish, Maggi. Statistical analysis: Isidori, Corona.

Obtaining funding: None.

Administrative, technical, or material support: None.

Supervision: Isidori, Buvat, Corona, Goldstein, Jannini, Lenzi, Porst, Salonia, Traish, Maggi.

Other (specify): None.

Financial disclosures: Mario Maggi certifies that all conflicts of interest, including specific financial interests and relationships and affiliations relevant to the subject matter or materials discussed in the manuscript (eg, employment/affiliation, grants or funding, consultancies, honoraria, 
stock ownership or options, expert testimony, royalties, or patents filed, received, or pending), are the following: Mario Maggi received consultancies and honoraria from Bayer, Lilly, Menarini, and Prostrakan. Andrea M. Isidori received consultancies from Bayer, Otsuka, and Beshin. Jacques Buvat received consultancies and honoraria from Eli Lilly, NextMed, Johnson \& Johnson, and Menarini. Giovanni Corona received speakers' honoraria from Lilly, Bayer, and Menarini. Irwin Goldstein received consultancies and honoraria from AbbVie, Auxilium, Eli Lilly, and Slate, and he received research funding from Clarus, Ferring, and Repros. Emmanule A. Jannini received speakers' honoraria from Menarini, Pfizer, Bayer, Janssen, Ibsa, and Lilly. Andrea Lenzi received unconditional research grants from Lilly and Serono. Hartmut Porst received consultancies and honoraria from Bayer and Lilly. Andrea Salonia received consultancies from Bayer International and Lilly Italia. Abdulmaged Traish has nothing to disclose.

Funding/Support and role of the sponsor: None.

\section{Appendix A. Supplementary data}

Supplementary data associated with this article can be found, in the online version, at http://dx.doi.org/10.1016/ j.eururo.2013.08.048.

\section{References}

[1] Salonia A, Castagna G, Sacca A, et al. Is erectile dysfunction a reliable proxy of general male health status? The case for the international index of erectile function-erectile function domain. J Sex Med 2012; 9:2708-15.

[2] Hall SA, Shackelton R, Rosen RC, Araujo AB. Sexual activity, erectile dysfunction, and incident cardiovascular events. Am J Cardiol 2010; 105:192-7.

[3] Montorsi F, Briganti A, Salonia A, et al. Erectile dysfunction prevalence, time of onset and association with risk factors in 300 consecutive patients with acute chest pain and angiographically documented coronary artery disease. Eur Urol 2003;44:360-4.

[4] Wu FC, Tajar A, Beynon JM, et al. Identification of late-onset hypogonadism in middle-aged and elderly men. N Engl J Med 2010; 363:123-35.

[5] Corona G, Rastrelli G, Monami M, et al. Hypogonadism as a risk factor for cardiovascular mortality in men: a meta-analytic study. Eur J Endocrinol 2011;165:687-701.

[6] Nicolosi A, Buvat J, Glasser DB, Hartmann U, Laumann EO, Gingell C. Sexual behaviour, sexual dysfunctions and related help seeking patterns in middle-aged and elderly Europeans: the global study of sexual attitudes and behaviors. World J Urol 2006;24:423-8.

[7] Salonia A, Ferrari M, Sacca A, et al. Delay in seeking medical help in patients with new-onset erectile dysfunction remained high over and despite the PDE5 era-an ecological study. J Sex Med 2012;9: 3239-46.

[8] Tsertsvadze A, Fink HA, Yazdi F, et al. Oral phosphodiesterase-5 inhibitors and hormonal treatments for erectile dysfunction: a systematic review and meta-analysis. Ann Intern Med 2009;151: 650-61.

[9] Kohler TS, Kim J, Feia K, et al. Prevalence of androgen deficiency in men with erectile dysfunction. Urology 2008;71:693-7.

[10] Wang C, Nieschlag E, Swerdloff R, et al. Investigation, treatment, and monitoring of late-onset hypogonadism in males: ISA, ISSAM, EAU, EAA, and ASA recommendations. J Androl 2009;30:1-9.

[11] Buvat J, Maggi M, Gooren L, et al. Endocrine aspects of male sexual dysfunctions. J Sex Med 2010;7:1627-56.
[12] Hatzimouratidis K, Amar E, Eardley I, et al. Guidelines on male sexual dysfunction: erectile dysfunction and premature ejaculation. Eur Urol 2010;57:804-14.

[13] Giannetta E, Gianfrilli D, Barbagallo F, Isidori AM, Lenzi A. Subclinical male hypogonadism. Best Pract Res Clin Endocrinol Metab 2012;26: 539-50.

[14] Tajar A, Forti G, O'Neill TW, et al. Characteristics of secondary, primary, and compensated hypogonadism in aging men: evidence from the European Male Ageing Study. J Clin Endocrinol Metab 2010;95:1810-8

[15] Radicioni AF, De Marco E, Gianfrilli D, et al. Strategies and advantages of early diagnosis in Klinefelter's syndrome. Mol Hum Reprod 2010;16:434-40.

[16] Filippi S, Vignozzi L, Morelli A, et al. Testosterone partially ameliorates metabolic profile and erectile responsiveness to PDE5 inhibitors in an animal model of male metabolic syndrome. J Sex Med 2009;6:3274-88.

[17] Hull EM, Lorrain DS, Du J, et al. Hormone-neurotransmitter interactions in the control of sexual behavior. Behav Brain Res 1999; 105:105-16.

[18] Mills TM, Lewis RW, Stopper VS. Androgenic maintenance of inflow and veno-occlusion during erection in the rat. Biol Reprod 1998;59: 1413-8.

[19] Lugg J, Ng C, Rajfer J, Gonzalez-Cadavid N. Cavernosal nerve stimulation in the rat reverses castration-induced decrease in penile NOS activity. Am J Physiol 1996;271:E354-61.

[20] Giuliano F, Rampin O, Schirar A, Jardin A, Rousseau JP. Autonomic control of penile erection: modulation by testosterone in the rat. $\mathrm{J}$ Neuroendocrinol 1993;5:677-83.

[21] Traish AM, Park K, Dhir V, Kim NN, Moreland RB, Goldstein I. Effects of castration and androgen replacement on erectile function in a rabbit model. Endocrinology 1999;140:1861-8.

[22] Reilly CM, Lewis RW, Stopper VS, Mills TM. Androgenic maintenance of the rat erectile response via a non-nitric-oxide-dependent pathway. J Androl 1997;18:588-94.

[23] Reilly CM, Stopper VS, Mills TM. Androgens modulate the alphaadrenergic responsiveness of vascular smooth muscle in the corpus cavernosum. J Androl 1997;18:26-31.

[24] Morelli A, Filippi S, Mancina R, et al. Androgens regulate phosphodiesterase type 5 expression and functional activity in corpora cavernosa. Endocrinology 2004;145:2253-63.

[25] Zhang XH, Morelli A, Luconi M, et al. Testosterone regulates PDE5 expression and in vivo responsiveness to tadalafil in rat corpus cavernosum. Eur Urol 2005;47:409-16.

[26] Yang R, Huang YC, Lin G, et al. Lack of direct androgen regulation of PDE5 expression. Biochem Biophys Res Commun 2009;380: 758-62.

[27] Andric SA, Janjic MM, Stojkov NJ, Kostic TS. Testosterone-induced modulation of nitric oxide-cGMP signaling pathway and androgenesis in the rat Leydig cells. Biol Reprod 2010;83:434-42.

[28] Morelli A, Comeglio P, Filippi S, et al. Mechanism of action of phosphodiesterase type 5 inhibition in metabolic syndromeassociated prostate alterations: an experimental study in the rabbit. Prostate 2013;73:428-41.

[29] Traish AM, Toselli P, Jeong SJ, Kim NN. Adipocyte accumulation in penile corpus cavernosum of the orchiectomized rabbit: a potential mechanism for veno-occlusive dysfunction in androgen deficiency. J Androl 2005;26:242-8.

[30] Baskin LS, Sutherland RS, DiSandro MJ, Hayward SW, Lipschutz J, Cunha GR. The effect of testosterone on androgen receptors and human penile growth. J Urol 1997;158:1113-8.

[31] Boas M, Boisen KA, Virtanen HE, et al. Postnatal penile length and growth rate correlate to serum testosterone levels: a longitudinal study of 1962 normal boys. Eur J Endocrinol 2006;154:125-9. 
[32] Traish AM, Hassani J, Guay AT, Zitzmann M, Hansen ML. Adverse side effects of 5alpha-reductase inhibitors therapy: persistent diminished libido and erectile dysfunction and depression in a subset of patients. J Sex Med 2011;8:872-84.

[33] Pinsky MR, Gur S, Tracey AJ, Harbin A, Hellstrom WJ. The effects of chronic 5-alpha-reductase inhibitor (dutasteride) treatment on rat erectile function. J Sex Med 2011;8:3066-74.

[34] Liu PY, Erkkila K, Lue Y, et al. Genetic, hormonal, and metabolomic influences on social behavior and sex preference of XXY mice. Am J Physiol Endocrinol Metab 2010;299:E446-55.

[35] Ward IL, Bennett AL, Ward OB, Hendricks SE, French JA. Androgen threshold to activate copulation differs in male rats prenatally exposed to alcohol, stress, or both factors. Horm Behav 1999;36: $129-40$.

[36] Corona G, Mannucci E, Ricca V, et al. The age-related decline of testosterone is associated with different specific symptoms and signs in patients with sexual dysfunction. Int J Androl 2009; 32: $720-8$.

[37] Kwan M, Greenleaf WJ, Mann J, Crapo L, Davidson JM. The nature of androgen action on male sexuality: a combined laboratory-selfreport study on hypogonadal men. J Clin Endocrinol Metab 1983; 57:557-62.

[38] Rhoden EL, Teloken C, Sogari PR, Souto CA. The relationship of serum testosterone to erectile function in normal aging men. J Urol 2002;167:1745-8.

[39] O'Connor DB, Lee DM, Corona G, et al. The relationships between sex hormones and sexual function in middle-aged and older European men. J Clin Endocrinol Metab 2011;96:E1577-87.

[40] Gray PB, Singh AB, Woodhouse LJ, et al. Dose-dependent effects of testosterone on sexual function, mood, and visuospatial cognition in older men. J Clin Endocrinol Metab 2005;90:3838-46.

[41] Buena F, Swerdloff RS, Steiner BS, et al. Sexual function does not change when serum testosterone levels are pharmacologically varied within the normal male range. Fertil Steril 1993;59: 1118-23.

[42] Basar MM, Aydin G, Mert HC, et al. Relationship between serum sex steroids and Aging Male Symptoms score and International Index of Erectile Function. Urology 2005;66:597-601.

[43] Bancroft J, Wu FC. Changes in erectile responsiveness during androgen replacement therapy. Arch Sex Behav 1983;12:59-66.

[44] Wang C, Cunningham G, Dobs A, et al. Long-term testosterone gel (AndroGel) treatment maintains beneficial effects on sexual function and mood, lean and fat mass, and bone mineral density in hypogonadal men. J Clin Endocrinol Metab 2004;89:2085-98.

[45] Giltay EJ, Tishova YA, Mskhalaya GJ, Gooren LJ, Saad F, Kalinchenko SY. Effects of testosterone supplementation on depressive symptoms and sexual dysfunction in hypogonadal men with the metabolic syndrome. J Sex Med 2010;7:2572-82.

[46] Hackett G, Cole N, Bhartia M, Kennedy D, Raju J, Wilkinson P. Testosterone replacement therapy with long-acting testosterone undecanoate improves sexual function and quality-of-life parameters vs. placebo in a population of men with type 2 diabetes. J Sex Med 2013;10:1612-27.

[47] Zitzmann M, Mattern A, Hanisch J, Gooren L, Jones H, Maggi M. IPASS: A study on the tolerability and effectiveness of injectable testosterone undecanoate for the treatment of male hypogonadism in a worldwide sample of 1,438 men. J Sex Med 2013;10:579-88.

[48] Isidori AM, Giannetta E, Gianfrilli D, et al. Effects of testosterone on sexual function in men: results of a meta-analysis. Clin Endocrinol (Oxf) 2005;63:381-94.

[49] Bolona ER, Uraga MV, Haddad RM, et al. Testosterone use in men with sexual dysfunction: a systematic review and meta-analysis of randomized placebo-controlled trials. Mayo Clin Proc 2007;82: 20-8.
[50] Cavallini G, Caracciolo S, Vitali G, Modenini F, Biagiotti G. Carnitine versus androgen administration in the treatment of sexual dysfunction, depressed mood, and fatigue associated with male aging. Urology 2004;63:641-6.

[51] Chiang HS, Hwang TI, Hsui YS, et al. Transdermal testosterone gel increases serum testosterone levels in hypogonadal men in Taiwan with improvements in sexual function. Int J Impot Res 2007;19: 411-7.

[52] Chiang HS, Cho SL, Lin YC, Hwang TI. Testosterone gel monotherapy improves sexual function of hypogonadal men mainly through restoring erection: evaluation by IIEF score. Urology 2009;73:762-6.

[53] Seftel AD, Mack RJ, Secrest AR, Smith TM. Restorative increases in serum testosterone levels are significantly correlated to improvements in sexual functioning. J Androl 2004;25:963-72.

[54] Saad F, Aversa A, Isidori AM, Zafalon L, Zitzmann M, Gooren L. Onset of effects of testosterone treatment and time span until maximum effects are achieved. Eur J Endocrinol 2011;165:675-85.

[55] Buvat J, Lemaire A, Buvat-Herbaut M. Human chorionic gonadotropin treatment of nonorganic erectile failure and lack of sexual desire: a double-blind study. Urology 1987;30:216-9.

[56] Guay AT, Bansal S, Heatley GJ. Effect of raising endogenous testosterone levels in impotent men with secondary hypogonadism: double blind placebo-controlled trial with clomiphene citrate. J Clin Endocrinol Metab 1995;80:3546-52.

[57] Moskovic DJ, Katz DJ, Akhavan A, Park K, Mulhall JP. Clomiphene citrate is safe and effective for long-term management of hypogonadism. BJU Int 2012;110:1524-8.

[58] Hsieh TC, Pastuszak AW, Hwang K, Lipshultz LI. Concomitant intramuscular human chorionic gonadotropin preserves spermatogenesis in men undergoing testosterone replacement therapy. J Urol 2013;189:647-50.

[59] Jannini EA, Screponi E, Carosa E, et al. Lack of sexual activity from erectile dysfunction is associated with a reversible reduction in serum testosterone. Int J Androl 1999;22:385-92.

[60] Jannini EA, Isidori AM, Gravina GL, et al. The ENDOTRIAL study: a spontaneous, open-label, randomized, multicenter, crossover study on the efficacy of sildenafil, tadalafil, and vardenafil in the treatment of erectile dysfunction. J Sex Med 2009;6:2547-60.

[61] Spitzer M, Basaria S, Travison TG, et al. Effect of testosterone replacement on response to sildenafil citrate in men with erectile dysfunction: a parallel, randomized trial. Ann Intern Med 2012;157: 681-91.

[62] Aversa A, Bruzziches R, Francomano D, et al. Effects of testosterone undecanoate on cardiovascular risk factors and atherosclerosis in middle-aged men with late-onset hypogonadism and metabolic syndrome: results from a 24-month, randomized, double-blind, placebo-controlled study. J Sex Med 2010;7:3495-503.

[63] Corona G, Jannini EA, Lotti F, et al. Premature and delayed ejaculation: two ends of a single continuum influenced by hormonal milieu. Int J Androl 2011;34:41-8.

[64] Shamloul R, Ghanem H, Fahmy I, et al. Testosterone therapy can enhance erectile function response to sildenafil in patients with PADAM: a pilot study. J Sex Med 2005;2:559-64.

[65] Buvat J, Montorsi F, Maggi M, et al. Hypogonadal men nonresponders to the PDE5 inhibitor tadalafil benefit from normalization of testosterone levels with a $1 \%$ hydroalcoholic testosterone gel in the treatment of erectile dysfunction (TADTEST study). J Sex Med 2011; 8:284-93.

[66] Corona G, Maggi M. The role of testosterone in erectile dysfunction. Nat Rev Urol 2010;7:46-56.

[67] Fabbri A, Giannetta E, Lenzi A, Isidori AM. Testosterone treatment to mimic hormone physiology in androgen replacement therapy. A view on testosterone gel and other preparations available. Expert Opin Biol Ther 2007;7:1093-106. 
[68] Zitzmann M. Pharmacogenetics of testosterone replacement therapy. Pharmacogenomics 2009;10:1341-9.

[69] Morgentaler A, Traish AM. Shifting the paradigm of testosterone and prostate cancer: the saturation model and the limits of androgen-dependent growth. Eur Urol 2009;55:310-20.

[70] Roddam AW, Allen NE, Appleby P, Key TJ. Endogenous sex hormones and prostate cancer: a collaborative analysis of 18 prospective studies. J Natl Cancer Inst 2008;100:170-83.

[71] Gacci M, Corona G, Salvi M, et al. A systematic review and metaanalysis on the use of phosphodiesterase 5 inhibitors alone or in combination with alpha-blockers for lower urinary tract symptoms due to benign prostatic hyperplasia. Eur Urol 2012;61:994-1003.

[72] Basaria S, Coviello AD, Travison TG, et al. Adverse events associated with testosterone administration. N Engl J Med 2010;363:109-22.

[73] Fernandez-Balsells MM, Murad MH, Lane M, et al. Clinical review 1: Adverse effects of testosterone therapy in adult men: a systematic review and meta-analysis. J Clin Endocrinol Metab 2010;95:2560-75.

[74] Haddad RM, Kennedy CC, Caples SM, et al. Testosterone and cardiovascular risk in men: a systematic review and meta-analysis of randomized placebo-controlled trials. Mayo Clin Proc 2007;82:29-39.

[75] Xu L, Freeman G, Cowling BJ, Schooling CM. Testosterone therapy and cardiovascular events among men: a systematic review and meta-analysis of placebo-controlled randomized trials. BMC Med 2013;11:108.

[76] Mathur A, Malkin C, Saeed B, Muthusamy R, Jones TH, Channer K. Long-term benefits of testosterone replacement therapy on angina threshold and atheroma in men. Eur J Endocrinol 2009;161: 443-9.

[77] Pasquali D, Arcopinto M, Renzullo A, et al. Cardiovascular abnormalities in Klinefelter Syndrome. Int J Cardiol 2013;168:754-9.

[78] Giannetta E, Isidori AM, Galea N, et al. Chronic inhibition of cGMP phosphodiesterase 5A improves diabetic cardiomyopathy: a randomized, controlled clinical trial using magnetic resonance imaging with myocardial tagging. Circulation 2012;125:2323-33.

[79] Buvat J, Maggi M, Guay A, Torres LO. Testosterone deficiency in men: systematic review and standard operating procedures for diagnosis and treatment. J Sex Med 2013;10:245-84.

[80] Dohle GR, Arver S, Bettocchi S, Kliesch M, Punab M, de Ronde W. Guidelines on male hypogonadism. European Association of Urology Web site. http://www.uroweb.org/gls/pdf/16_Male_ Hypogonadism_LR\%20II.pdf. Updated 2012.

[81] Bhasin S, Cunningham GR, Hayes FJ, et al. Testosterone therapy in men with androgen deficiency syndromes: an Endocrine Society clinical practice guideline. J Clin Endocrinol Metab 2010;95:2536-59.

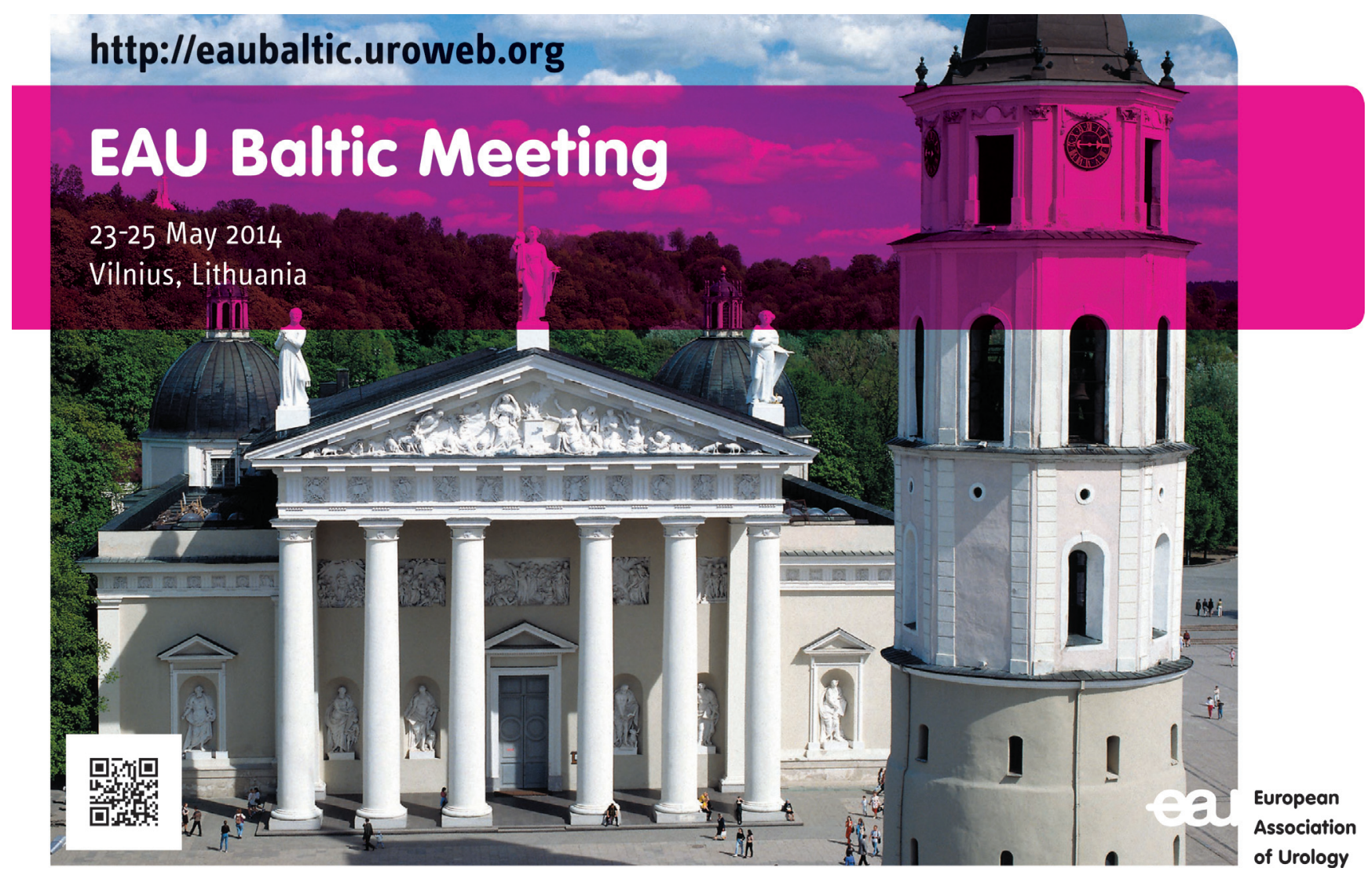

